Arq. Bras. Med. Vet. Zootec., v.63, n.2, p.448-455, 2011

\title{
Biodisponibilidade de fontes orgânicas e inorgânicas de zinco em ovinos
}

\author{
[Bioavailability of organic and inorganic zinc sources in sheep] \\ F.G. Vilela ${ }^{1}$, M.A. Zanetti ${ }^{2}$, A. Saran Netto ${ }^{2}$, J.E. Freitas Junior ${ }^{4}$, C.Y.C. Yoshikawa ${ }^{3}$ \\ ${ }^{1}$ Departamento de Nutrição e Produção Animal - FMVZ/USP \\ Av. Duque de Caxias Norte, 225 \\ 13635-900 - Pirassununga, SP \\ ${ }^{2}$ Departamento de Zootecnia- FZEA/USP \\ ${ }^{3}$ Aluna de pós-graduação - FZEA/USP \\ ${ }^{4}$ Aluno de pós-graduação - Universidade Estadual Júlio de Mesquita-UNESP - Jaboticabal, SP
}

\section{RESUMO}

Compararam-se os efeitos de diferentes fontes e doses de zinco na dieta de ovinos Santa Inês sobre os níveis de zinco plasmático e de fosfatase alcalina. Foram utilizados 40 cordeiros, recém-desmamados, com média de peso de 18,4kg, distribuídos em 10 tratamentos: 1- dieta basal sem suplementação de zinco; 2- dieta basal + 200mg de Zn/kg de MS na forma de óxido de zinco; 3- dieta basal + 400mg de $\mathrm{Zn} / \mathrm{kg}$ de MS na forma de óxido de zinco; 4- dieta basal $+600 \mathrm{mg}$ de Zn/kg de MS na forma de óxido de zinco; 5- dieta basal + 200mg de Zn/kg de MS na forma de zinco aminoácido; 6- dieta basal + 400mg de $\mathrm{Zn} / \mathrm{kg}$ de MS na forma de zinco aminoácido; 7- dieta basal $+600 \mathrm{mg}$ de Zn/kg de MS na forma de zinco aminoácido; 8- dieta basal + 200mg de Zn/kg de MS na forma de zinco proteinato; 9- dieta basal + $400 \mathrm{mg}$ de $\mathrm{Zn} / \mathrm{kg}$ de MS na forma de zinco proteinato; 10- dieta basal $+600 \mathrm{mg}$ de $\mathrm{Zn} / \mathrm{kg}$ de MS na forma de zinco proteinato. A cada 28 dias, os animais foram pesados e tiveram seu sangue colhido para análise de zinco (Zn), análise de fosfatase alcalina e análises de imunoglobulinas G (IgG) e M (IgM). No final do experimento, foram coletadas amostras de fígado para estudo dos níveis de zinco hepático. Não houve diferença entre tratamentos nos níveis de fosfatase alcalina e de zinco hepático, e no ganho de peso $(\mathrm{P}>0,05)$, mas houve diferença $(\mathrm{P}<0,05)$ nos níveis de Zn plasmático e nos níveis de IgG e IgM. Baseando-se no acúmulo no fígado, a estimativa da biodisponibilidade de zinco, por intermédio das equações de regressão, mostrou que as fontes orgânicas e inorgânicas de zinco não diferiram entre si.

Palavras-chave: cordeiro, biodisponibilidade, zinco, minerais

\begin{abstract}
This research was done to compare the effects of different zinc sources and doses in the Santa Ines sheep diet. Forty lambs at weaning, with $18,4 \mathrm{~kg} B W$ were randomly allotted and fed 10 treatments: 1 - base diet without zinc supplementation; 2- base diet $+200 \mathrm{mg} \mathrm{Zn} / \mathrm{kg}$ of DM as zinc oxide; 3- base diet $+400 \mathrm{mg}$ $\mathrm{Zn} / \mathrm{kg}$ of DM as zinc oxide; 4- base diet $+600 \mathrm{mg} \mathrm{Zn} / \mathrm{kg}$ of DM as zinc oxide; 5 - base diet $+200 \mathrm{mg} \mathrm{Zn} / \mathrm{kg}$ of DM as amino acid zinc; 6- base diet $+400 \mathrm{mg} \mathrm{Zn} / \mathrm{kg}$ of DM as amino acid zinc; 7- base diet $+600 \mathrm{mg}$ $\mathrm{Zn} / \mathrm{kg}$ of DM as amino acid zinc; 8- base diet $+200 \mathrm{mg} \mathrm{Zn/kg}$ of DM as proteinato zinc; 9- base diet + $400 \mathrm{mg} \mathrm{Zn} / \mathrm{kg}$ of DM as proteinato zinc; 10 - base diet $+600 \mathrm{mg} \mathrm{Zn} / \mathrm{kg}$ of DM as proteinato zinc. The animals were weighed and sampled for blood zinc analysis, phosphatase alkaline analysis and immunoglobulins $G$ and $M$ analysis. At the end of the experiment liver samples were collected to study the zinc hepatic levels. There was no difference in phosphatase alkaline levels, hepatic zinc levels and weight gain $(P>0,05)$ but differences $(P<0,05)$ in plasmatic zinc levels and in IgG and IgM levels were observed. Based on liver tissue uptake, estimates of the zinc bioavailability, through the regression equations showed that the organic and inorganic sources of zinc did not differ.
\end{abstract}

Keywords: lamb, bioavailability, minerals, zinc

Recebido em 16 de março de 2010

Aceito em 17 de março de 2011

E-.mail: fgvilela@usp.br 


\section{INTRODUÇÃO}

Os minerais estão presentes em quantidades variáveis nos alimentos comumente oferecidos aos ruminantes. Muitas vezes, a concentração de um ou mais minerais nos alimentos ou na dieta não atendem às exigências nutricionais dos animais para um determinado propósito produtivo. Neste caso, é necessária a suplementação da dieta com fontes de minerais. Dentre as formas mais comuns de suplementação, está a iônica (cloretos, sulfatos, óxidos, hidróxidos, carbonatos). Entretanto, algumas dessas fontes, principalmente quando se trata de microminerais, apresentam baixa absorção no organismo animal ou baixa biodisponibilidade (Spears, 1989).

A absorção de zinco ocorre, principalmente, no intestino delgado, com destaque para o duodeno, local onde é mais acentuada. Animais com deficiência apresentam maior capacidade de absorver zinco do que aqueles que apresentam taxas normais do elemento em seu organismo (Mertz, 1996). Em ruminantes, o fígado apresenta maior teor de zinco do que o osso, assim deve ser o tecido preferido para se realizar estudos de acúmulo, segundo Fick et al. (1989).

O zinco faz parte de um grande número de enzimas e ainda atua como cofator de outras. Sua deficiência em ruminantes causa redução no crescimento, na ingestão de alimentos e na conversão alimentar, além de problemas ósseos e diminuição da imunidade. No Brasil (Tokarnia et al., 1999), já foram diagnosticados níveis baixos de zinco na maioria das regiões, em diferentes épocas do ano. Há uma grande variação no teor de zinco tanto no solo quanto nas forragens. Para diagnosticar a deficiência, o teor de zinco sanguíneo é bastante utilizado, e teores entre 0,4 e $0,6 \mathrm{mg} / \mathrm{kg}$ são considerados deficientes, podendo causar lesões severas nos ruminantes (McDowell, 1992). Segundo Underwood (1993), os teores de zinco plasmáticos considerados normais para ovinos variam de 0,61 a $0,89 \mathrm{mg} / \mathrm{kg}$, com média de $0,75 \mathrm{mg} / \mathrm{kg}$.

A deficiência de zinco pode ser desencadeada pela presença de substâncias inibidoras da dieta, pela simples falta do elemento na dieta, quando se instalam processos infecciosos, agudos ou crônicos, e em condições de estresse prolongado. Quando ocorre estresse, há mobilização de uma proteína, denominada metalotioneína, dependente de zinco. Essa proteína funciona como agente vigilante do órgão que necessita de zinco para sua manutenção e função, assim mobiliza o zinco endógeno e armazena-o no fígado. Esse mecanismo tem a função de manter a integridade do sistema de defesa contra agentes infecciosos (bactérias, vírus, toxinas) e atua na regeneração do tecido lesado.

Em condições de alto estresse, há prioridade do zinco para o sistema imunológico, a fim de fortalecer o mecanismo de defesa. Desse modo, a síntese de queratina, proteína integrante da pele e dos pelos, tem menor prioridade, e podem ocorrer alopecia e paraqueratose (Peixoto et al., 1994). Quando a deficiência de zinco se estabelece, ocorre atrofia do timo, principal órgão do sistema imune, com perda da função normal das células $\mathrm{T}$ (resposta celular) e diminuição das células B (resposta humoral) (Hambidge et al., 1996). A deficiência prolongada de zinco pode ser demonstrada pela depressão na produção de imunoglobulinas $G$ e M.

Para a realização de estudos de biodisponibilidade com teores de zinco nas dietas próximos ao recomendado, 30mg/kg de matéria seca (Nutrient..., 2007), torna-se necessária uma dieta basal purificada, sem a presença de zinco, ou dieta com teores muito baixos. Devido à dificuldade de se formular uma dieta purificada, levando em consideração que os alimentos utilizados para ovinos possuem zinco, recomenda-se usar dietas com altos níveis de zinco. Ammerman et al. (1995) preconizaram dietas com níveis altos do mineral investigado, a fim de se obter maior diferença nos parâmetros estudados.

O objetivo deste estudo foi comparar os efeitos de doses de zinco na dieta de ovinos Santa Inês utilizando-se fontes orgânicas e inorgânicas sobre parâmetros sanguíneos, resposta imunológica e desempenho.

\section{MATERIAL E MÉTODOS}

O experimento foi realizado durante 114 dias, sendo os primeiros 30 dias denominados período de depleção, no qual os animais receberam apenas a dieta basal sem suplementação adicional de zinco. Foram utilizados 40 cordeiros 
da raça Santa Inês, recém-desmamados, com média de idade de quatro meses, suplementados com três diferentes fontes de zinco - óxido de zinco, zinco aminoácido e zinco proteinato - e três doses de zinco - 200, 400 e $600 \mathrm{mg} / \mathrm{kg}$ de MS - adicionados à dieta basal. A fim de facilitar a mistura e dificultar a seleção pelo animal, foram utilizadas dietas completas com fibra incorporada através da casca de algodão (Zanetti e Cunha, 1997), conforme a composição percentual apresentada na Tab. 1 . No período de depleção e no início do experimento ( 0 a 28 dias), cada animal recebeu $800 \mathrm{~g}$ desta ração, na metade do experimento ( 28 a 56 dias), $900 \mathrm{~g}$, e no final do período experimental (56 a 84 dias), $1 \mathrm{~kg}$.

Tabela 1 - Composição percentual da dieta basal fornecida a ovinos

\begin{tabular}{lc}
\hline Ingrediente & $\%$ \\
\hline Fubá de milho & 55,3 \\
Farelo de trigo & 1,0 \\
Casca de algodão & 25,0 \\
Farelo de soja & 12,5 \\
Óleo de soja & 1,0 \\
Calcário & 1,2 \\
Fosfato bicálcico & 2,0 \\
Ureia & 1,0 \\
Mistura mineral vitamínica & 1,0 \\
Total & 100,0 \\
\hline
\end{tabular}

Os animais, com média de peso inicial de 18,4kg, foram distribuídos aleatoriamente em 10 tratamentos: 1- dieta basal sem suplementação de zinco; 2- dieta basal + 200mg de Zn/kg de MS na forma de óxido de zinco; 3- dieta basal + 400mg de $\mathrm{Zn} / \mathrm{kg}$ de MS na forma de óxido de zinco; 4dieta basal + 600mg de $\mathrm{Zn} / \mathrm{kg}$ de MS na forma de óxido de zinco; 5- dieta basal + 200mg de Zn/kg de MS na forma de zinco aminoácido; 6- dieta basal + 400mg de $\mathrm{Zn} / \mathrm{kg}$ de MS na forma de zinco aminoácido; 7- dieta basal + 600mg de Zn/kg de MS na forma de zinco aminoácido; 8dieta basal + 200mg de Zn/kg de MS na forma de zinco proteinato; 9- dieta basal $+400 \mathrm{mg}$ de $\mathrm{Zn} / \mathrm{kg}$ de MS na forma de zinco proteinato; 10dieta basal + 600mg de $\mathrm{Zn} / \mathrm{kg}$ de MS na forma de zinco proteinato. Os animais permaneceram individualmente em gaiolas, construídas de material plástico para evitar possíveis contaminações. Cada gaiola possuía um cocho para suplementação alimentar e um reservatório de água que foi fornecida ad libitum.

Os animais foram pesados a cada 28 dias e tiveram seu sangue colhido para análise de zinco plasmático, análise de fosfatase alcalina e análise dos níveis de imunoglobulinas $\mathrm{G}$ e $\mathrm{M}$. As análises de zinco foram feitas em espectrofotômero de absorção atômica (Miles et al., 2001), e, para as de fosfatase e imunoglobulinas, utilizaram-se kits LabTest. A fosfatase alcalina foi analisada pelo método Bowers Mc modificado (Quantitative..., 1982), e as análises de imunoglobulinas foram feitas pelo fracionamento eletroforético das proteínas plasmáticas em gel de agarose, com o tampão Tris-glicina, $\mathrm{pH}$ 9,5, em cada lado da cuba. As cubas foram fechadas e ligadas às fontes de $90 \mathrm{~V}$. A separação eletroforética teve duas etapas: a) diluição do plasma com água destilada e colocação de $0,6 \mu \mathrm{L}$ em cada poço do filme, levado para a cuba de eletroforese por 35 minutos; b) tratamento do plasma com 2Mercaptoetanol que, após a desidratação em sacos de diálise, foi usado para nova eletroforese. Com os resultados da concentração de proteínas plasmáticas totais, proteína do plasma integral por eletroforese e proteínas do plasma tratado pelo 2-Mercaptoetanol, foi possível determinar a concentração de imunoglobulinas $G$ e $M$. A leitura foi feita por um densitômetro Celm DS 35, comprimento de onda de 520 nanômetros.

No final do experimento, foram coletadas amostras de fígado para estudo dos níveis hepáticos de zinco. Essas amostras também foram analisadas em espectrofotômero de absorção atômica (Miles et al., 2001). Para estimar a biodisponibilidade relativa, por meio da técnica do slope ratio, é muito importante seguir um modelo experimental (Ammerman et al., 1995), que preconiza que a resposta aos níveis dos nutrientes comparados seja linear.

O delineamento estatístico foi o de blocos ao acaso, com quatro animais por tratamento. Usouse o pacote estatístico SAS (2000), analisando-se as variáveis por meio de contrastes pelo PROC GLM, para estudar o efeito dos tratamentos fontes e doses - e regressão, para estudar a biodisponibilidade. 


\section{RESULTADOS E DISCUSSÃO}

Na Fig. 1, são apresentados os níveis de zinco plasmático, com diferentes fontes de zinco, em diferentes tempos de coleta.

Houve diferença significativa $(\mathrm{P}<0,05)$ nos níveis plasmáticos de zinco em função das diferentes fontes e doses de zinco. Para McDowell (1992), níveis séricos de 0,60 a $0,80 \mathrm{mg} / \mathrm{kg}$ são considerados normais, assim todos os tratamentos, com exceção do Zn proteinato 200 e do tratamento-controle, apresentaram níveis acima do normal, indicando que a suplementação utilizada nos demais tratamentos foi maior que a absorção de zinco. As suplementações com óxido de zinco 600, óxido de zinco 400 e zinco proteinato 600 foram maiores $(\mathrm{P}<0,05)$ que a suplementação-controle, e este resultado, levando em consideração apenas os níveis plasmáticos de zinco como indicador da biodisponibilidade, indica que a fonte orgânica de Zn aminoácido, independentemente da dosagem utilizada, foi a que apresentou a menor absorção de zinco.

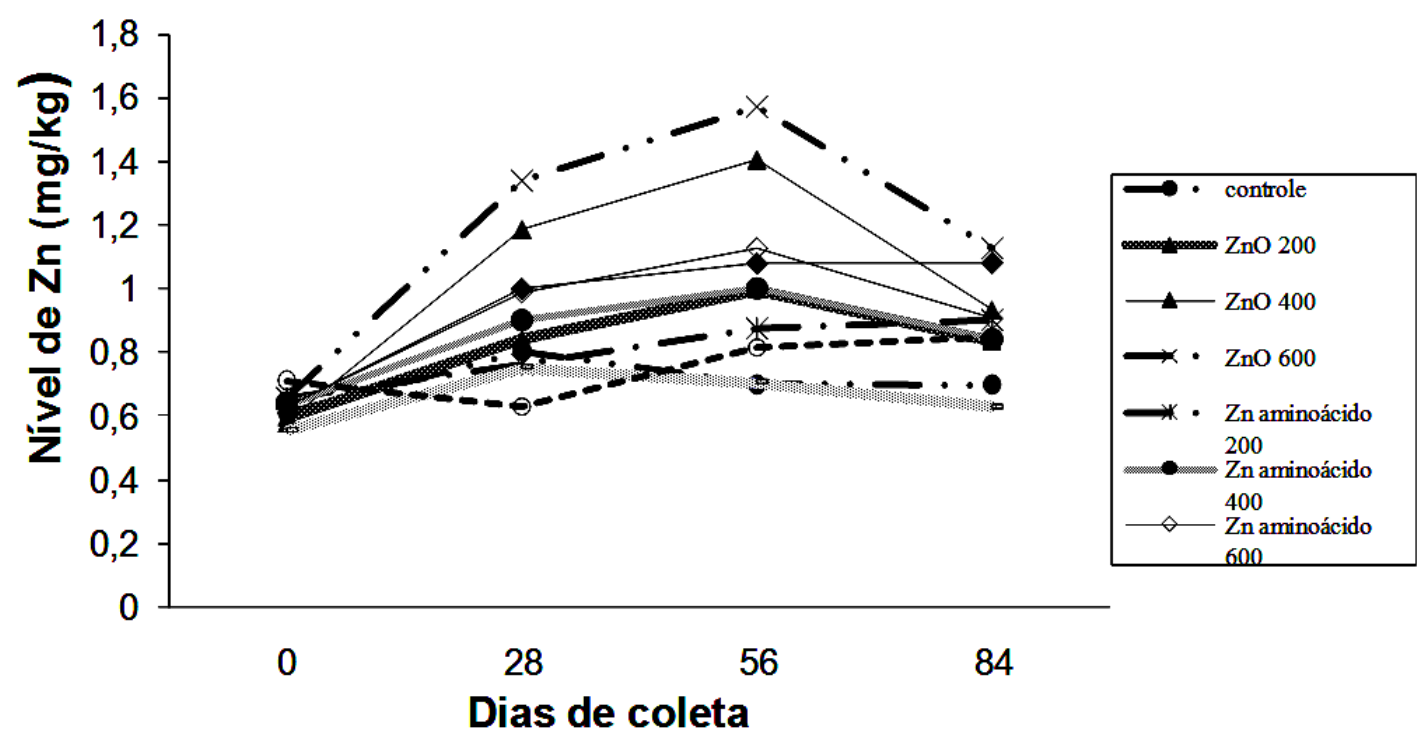

Figura 1. Níveis de zinco plasmático, em função dos dias de coleta, observados em ovinos, segundo as dietas.

Kincaid et al. (1997), ao realizarem um experimento para determinar o efeito do zinco tendo como fonte óxidos e aminoácidos, utilizando novilhos da raça Holandesa com dietas com níveis de 60, 150 e 300mg/kg de zinco, encontraram concentração mais elevada para zinco metionina e zinco lisina, mas não para o óxido de zinco.

Segundo Ammerman et al. (1995), para calcular a biodisponibilidade das variáveis, deve-se utilizar um melhor ponto para slope ratio, e o ponto que melhor representa esta diferença, conforme a Fig. 1, refere-se ao dia 56 de coleta.
Na Fig. 2, são apresentados os níveis de zinco plasmáticos em função dos níveis de suplementação de zinco de acordo com as fontes utilizadas, referentes ao dia 56 de coleta. Houve diferença significativa $(\mathrm{P}<0,05)$ nos níveis plasmáticos de zinco em função das diferentes fontes. A fonte zinco aminoácido foi a que apresentou menor absorção de zinco (Fig. 2), resultado semelhante ao apresentado na Fig.1.

Nas Fig. 3, 4 e 5, são apresentados os níveis de fosfatase alcalina e imunoglobulinas $\mathrm{G}$ e $\mathrm{M}$, segundo as fontes e os tempos de coleta. 


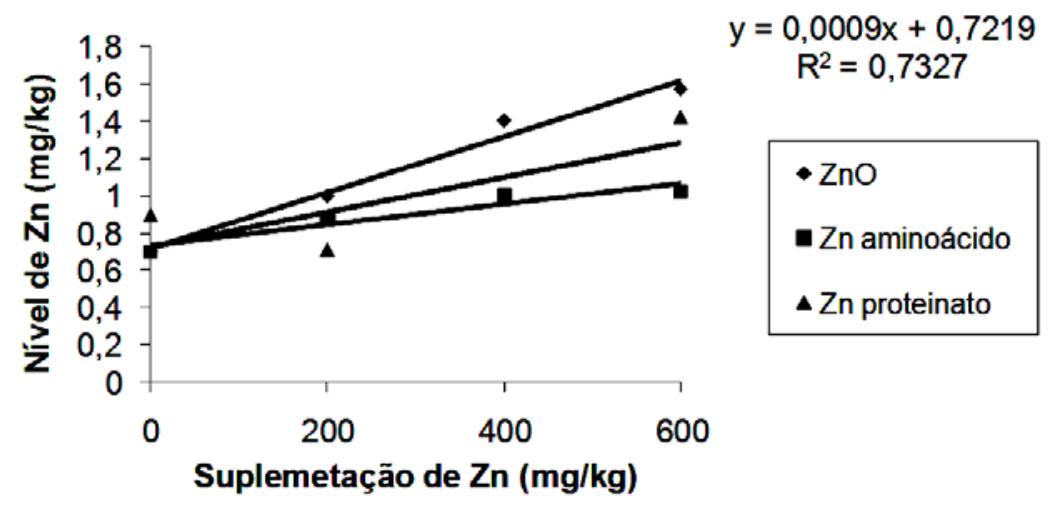

Figura 2. Níveis de zinco plasmáticos, em função da suplementação de zinco, observados em ovinos, segundo as dietas.

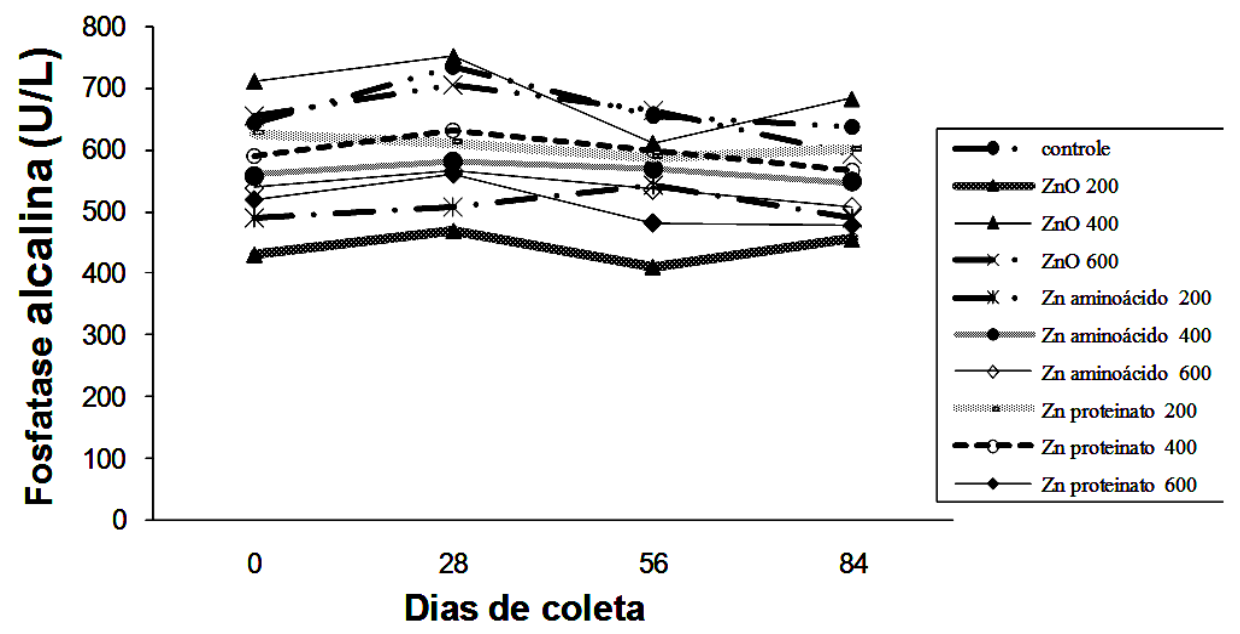

Figura 3. Níveis de fosfatase alcalina, em função dos dias de coleta, observados em ovinos, segundo as dietas.

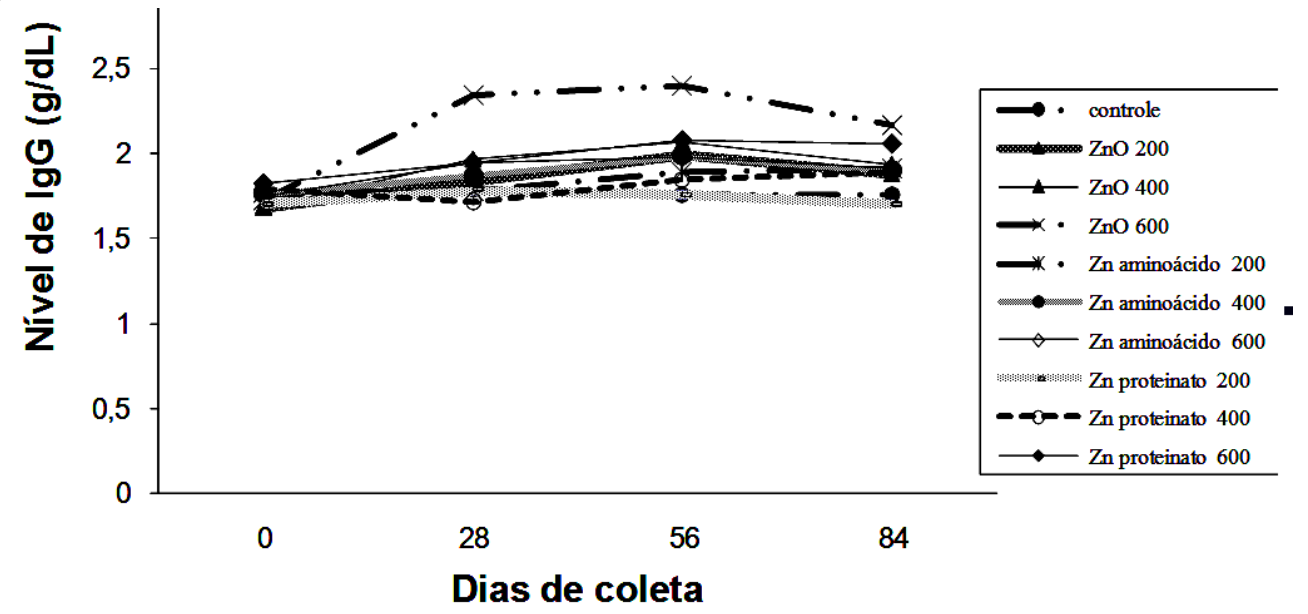

Figura 4. Níveis de imunoglobulina G, em função dos dias de coleta, observados em ovinos, segundo as dietas. 


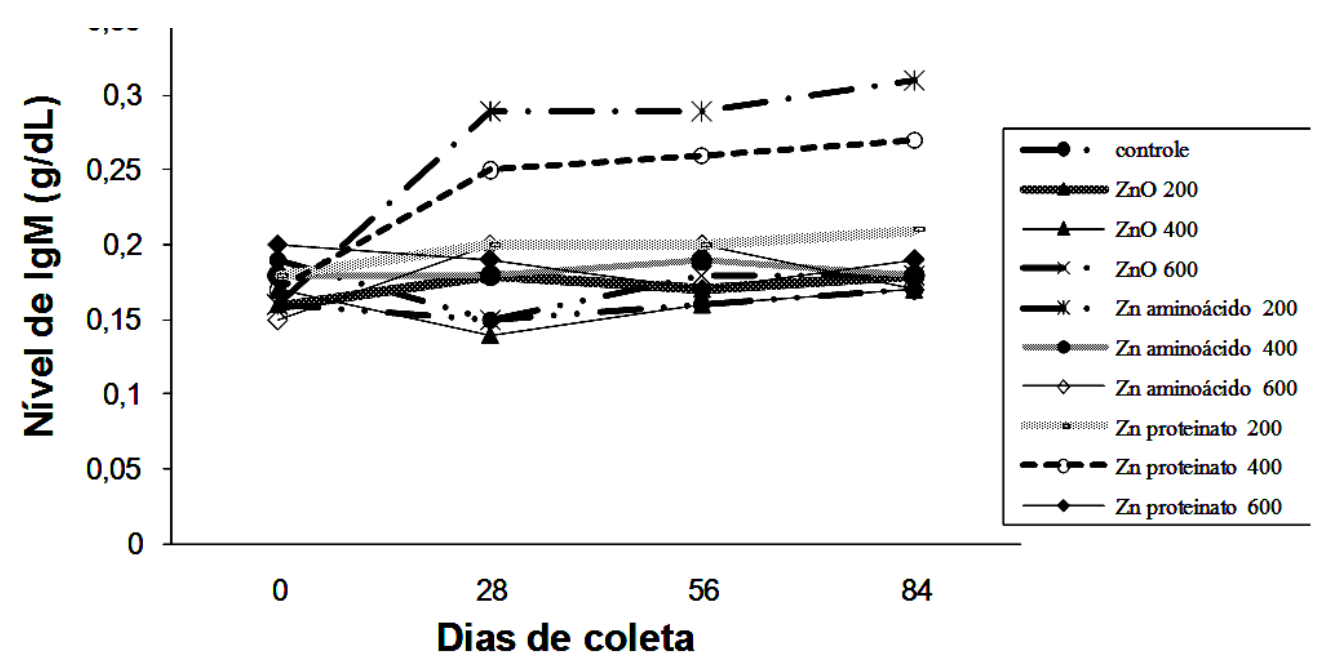

Figura 5. Níveis de imunoglobulina M, em função dos dias de coleta, observados em ovinos, segundo as dietas.

Não houve diferença significativa nos níveis de fosfatase alcalina em função das diferentes fontes de zinco $(\mathrm{P}>0,05)$. Assumindo-se que a atividade da fosfatase alcalina é um indicador de biodisponibilidade, pode-se afirmar, com base nos dados da Fig. 3, que a disponibilidade do zinco em óxido de zinco, zinco aminoácido e zinco proteinato, independentemente da dosagem utilizada, foi similar mesmo quando foram utilizados níveis crescentes de zinco. Apesar dos níveis plasmáticos altos de zinco quando se utilizou a suplementação com óxido de zinco 600, óxido de zinco 400 e zinco proteinato 600, estes não resultaram em maior atividade de fosfatase alcalina. Entretanto, a fosfatase alcalina pode ser influenciada por outros fatores, até mesmo pelo teor de fósforo na dieta. Considerando-se os altos níveis de zinco, eles podem ter provocado uma resposta similar entre as fontes.

Estes resultados são similares aos de Spears (1989), que trabalhou com fontes orgânicas e inorgânicas de zinco em 18 ovinos com idade entre quatro e cinco meses, e não encontrou teores mais elevados na atividade da fosfatase alcalina.

Houve diferença $(\mathrm{P}<0,05)$ nos níveis de imunoglobulina $G$ (IgG) em função das fontes e doses de zinco (Fig. 4). A curva obtida com óxido de zinco 600 ficou acima das demais a partir da coleta de 28 dias, sendo esta suplementação mais alta que a suplementaçãocontrole. A IgG é encontrada em maior concentração no sangue e, por essa razão, exerce o papel principal nos mecanismos de defesa mediados por anticorpos. Como a IgG é a menor das moléculas, ela pode escapar dos vasos sanguíneos mais facilmente que as outras moléculas de imunoglobulina. Isso é especialmente importante nos tecidos inflamados em que o aumento na permeabilidade vascular permite facilmente que a IgG participe da defesa do fluido tecidual e das superfícies corpóreas (Marcin e Cooper, 1992).

Houve diferença significativa $(\mathrm{P}<0,05)$ nos níveis de imunoglobulina M (IgM) em função das fontes e doses de zinco (Fig. 5). Os níveis de IgM aumentaram entre zero e 28 dias de coleta e assim se mantiveram tanto para o zinco aminoácido 200 como para o zinco proteinato 400, enquanto os outros níveis de IgM diminuíram ou permaneceram estáveis. A IgM é a segunda maior concentração de imunoglobulina na maioria do soro dos mamíferos. A IgM é a principal classe de imunoglobulina produzida durante uma resposta imune primária. Embora seja produzida em pequena quantidade, é consideravelmente mais eficiente que a IgG na ativação do complemento, opsonização, neutralização de vírus e aglutinação (Naessens et al., 1988). 
Não houve diferença significativa entre os tratamentos $(\mathrm{P}<0,05)$ em relação ao ganho de peso (Fig. 6). Os animais suplementados com a dieta basal foram os que apresentaram o pior desempenho, apesar de não ter havido diferença estatística. Este fato pode ser explicado pelo papel do zinco no organismo animal, onde está relacionado a enzimas, seja como parte da molécula, seja como ativador. O zinco, em particular, parece ser cofator de várias enzimas que estão envolvidas na síntese proteica, e, também, nas taxas de síntese e catabolismo de RNA e DNA. A utilização de aminoácidos para a síntese de proteínas é prejudicada quando há deficiência de zinco.

Os resultados para ganho de peso diferem dos encontrados por Ward et al. (1992), que encontraram maior ganho de peso para os animais que utilizaram zinco na forma orgânica.

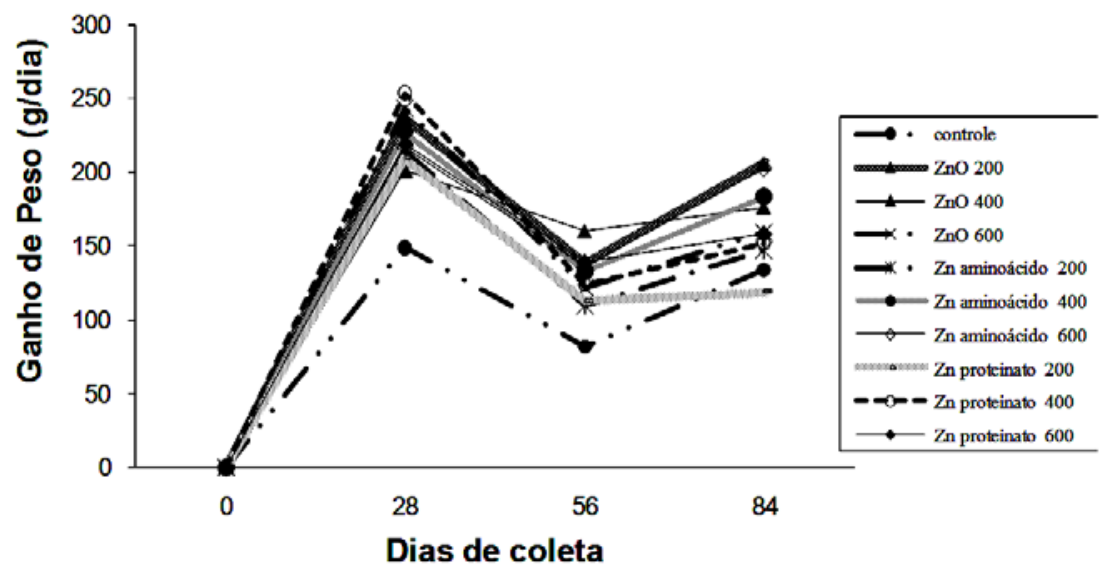

Figura 6. Ganhos de peso, em função dos dias de coleta, observados em ovinos, segundo as dietas.

Na Fig. 7, são apresentados os níveis de zinco hepático em função do teor de suplementação de zinco de acordo com as fontes utilizadas. Não houve diferença significativa entre os tratamentos $(\mathrm{P}>0,05)$ em relação aos níveis de zinco hepático. O nível de zinco no fígado do tratamento-controle foi, em média, de $137 \mathrm{mg} / \mathrm{kg}$ de MS, e nos tratamentos que utilizaram óxido de zinco, zinco aminoácido e zinco proteinato, de 136,47 a $255,45 \mathrm{mg} / \mathrm{kg}$ de MS. Segundo Puls (1988), níveis de zinco normais no fígado situam-se entre 75 e $300 \mathrm{mg} / \mathrm{kg}$ de MS, e, como observado na Fig. 7, os valores de zinco hepático encontram-se dentro desse intervalo. Apesar de não ter havido diferença significativa entre as fontes estudadas, os resultados das análises de fígado tenderam a ser menores para a fonte de óxido de zinco. Estes resultados são semelhantes aos de Miotto (1999), que trabalhou com 28 cordeiros, utilizando fontes orgânica e inorgânica de zinco em três níveis de suplementação, e também não encontrou diferença significativa em relação aos níveis de zinco no fígado.

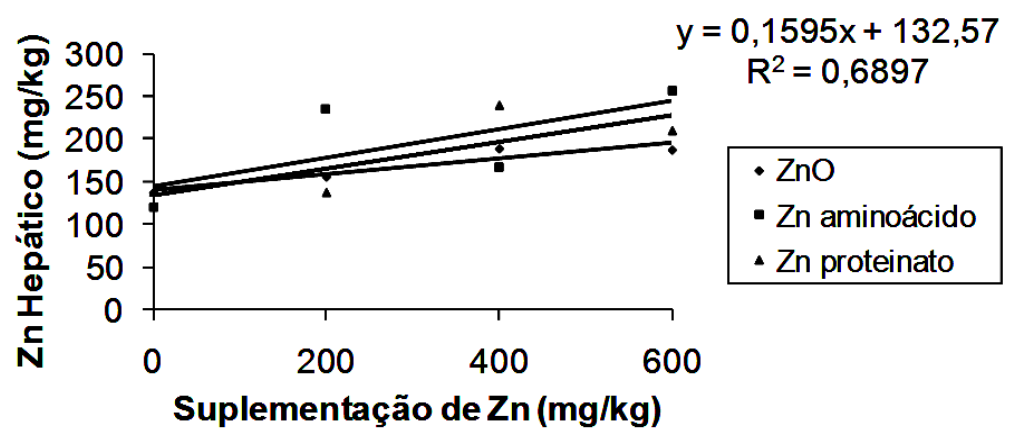

Figura 7. Níveis de zinco hepático, em função dos níveis de suplementação, observados em ovinos segundo as dietas. 


\section{CONCLUSÕES}

Baseando-se apenas no acúmulo hepático, a estimativa da biodisponibilidade de zinco, por intermédio das equações de regressão linear, mostrou que as fontes orgânicas e inorgânicas não diferiram entre si, apesar da melhor tendência de acúmulo hepático das fontes orgânicas. Assumindo-se que o nível plasmático de zinco, a atividade da fosfatase alcalina, os níveis de imunoglobulinas $\mathrm{G}$ e $\mathrm{M}$ e o ganho de peso são indicadores de biodisponibilidade, pode-se afirmar, com base neste experimento, que a disponibilidade do óxido de zinco foi melhor em pelo menos dois indicadores - níveis de zinco plasmático e de imunoglobulina $\mathrm{G}$ enquanto a disponibilidade do zinco aminoácido e do zinco proteinato foi melhor apenas em relação aos níveis de imunoglobulina $\mathrm{M}$.

\section{REFERÊNCIAS BIBLIOGRÁFICAS}

AMMERMAN, C.B.; BAKER, D.H.; LEWIS, A.J. Bioavailability of nutrients for animals. San Diego: Academic, 1995. 441p.

FICK, K. R.; McDOWELL, L.R.; MILES, P.H. et al. Methods of mineral analysis for plant and animal tissues. 2.ed. Gainesville: University of Florida, 1989. p.901-908

HAMBIDGE, K.M.; CASEY, C.E.; KREBS, N.F. Trace elements in human and animal nutrition. 5. ed. Orlando: Academic, 1996. p. 1109

KINCAID, L.R.; CHEW, B.P.; CRONRATH, J.D. Oxide and amino acids as sources of dietary zinc for calves: effects on uptake and immunity. J. Anim. Sci., v.80, p.1381-1388, 1997.

MARCIN, K.B.; COOPER, M.D. New views of the immunoglobulin heavy-chain switch. Nature, v. 298, p.327-328, 1992.

McDOWELL, L.R. Minerals in animal and human nutrition. New York: Academic, 1992. 524p.

MERTZ, W. Trace elements in human and nutrition. 5.ed. New York: Academic, 1996. p.1189-1192,

MILES, P.H.; WILKINSON, N.S.; McDOWELL, L.R. Analysis of mineral for animal nutrition research. 3.ed. Gainesville: University of Florida, 2001. 118p.
MIOTTO, C.M. Estudo da biodisponibilidade de zinco quelatado para ovinos. 1999. 46f. Dissertação (Mestrado) - Universidade de São Paulo, Pirassununga, SP.

NAESSENS, J.; NEWSON, J.; WILLIAMS, D.J.L. et al. Identification of classes and allotypes of bovine immunoglobulin $\mathrm{M}$ with monoclonal antibodies. Immunology, v. 63, p. 569-574, 1988.

NUTRIENT requirements of small ruminants, Washington: National Academy, 2007.

PEIXOTO, P.V.; MORAES, S.S.; LEMOS, R.A. Ocorrência da paraqueratose hereditária (linhagem letal A-46) no Brasil. Pesq. Vet. Bras., v.14, p.79-84, 1994.

PULS, R. Mineral levels in animal health: dianosty data. [s.l.]: Sherpa International, 1988. p.240.

QUANTITATIVE kinetic determination of alkaline phosphatase (AP) in serum or plasma at 405mm. Tech. Bull., n. 246, 1982.

SPEARS, J.W. Zinc methionine or ruminants: relative bioavailability of zinc in lambs and effects of growth and performance of growing heifers. J. Anim. Sci., v.67, p.835-843, 1989.

TOKARNIA, C.H.; DOBERAINER, J.; MORAES, S.S. et al. Deficiências minerais em bovinos e ovinos - Revisão dos estudos realizados no Brasil de 1987 a 1998. Pesq. Vet. Bras., v.19, p.47-62, 1999.

UNDERWOOD, E.J. The mineral nutrition of livestock. Rome: FAO, 1993.

WARD, J.D.; SPEARS, J.W.; KEGLEY, E.B. Effect of trace mineral source on mineral metabolism, performance and immune response in stressed cattle. J. Anim. Sci., v.70, suppl. 1, p.300, 1992. (Abstr.).

ZANETTI, M.A.; CUNHA, J.A. Biodisponibilidade de fontes orgânicas e inorgânicas de selênio. Rev. Soc. Bras. Zootec., v.26, p.623-627, 1997. 